\title{
Pulmonary Function Impairment among Stone Cutting Workers in North Gujarat
}

\author{
Vidhya Solanki ${ }^{1}$, Karishma Barot ${ }^{2}$, Priyanka Chaudhari ${ }^{3}$, Krupa Soni ${ }^{4}$ \\ ${ }^{1-3}$ Tutor, ${ }^{4}$ Assistant Professor, \\ Nootan College of Physiotherapy, Sankalchand Patel university, Visnagar, Gujarat, India 384315
}

Corresponding Author: Vidhya Solanki

\begin{abstract}
Background: Pulmonary problems are a major cause of morbidity \& mortality all over the world. It has been found that lung functions are mostly affected in workers exposed to affect majorly in granite, marble, various other rocks and sand dust exposed workers.

Objective: The primary objective of the study was to find out the prevalence of pulmonary function impairment among stone cutting workers at various construction sites in North Gujarat and the secondary objective was to find the effectiveness of Physiotherapy measures among those workers.

Methods: A total of 408 male stone cutting worker participated in this study around various construction sites in the vicinity of North Gujarat from September to December 2019. After assessing pulmonary function tests, workers with impairment were treated with Deep breathing exercise and advice personal protective measures like face masks, cession of smoking and water spraying before cutting.

Results: The data was collected from all the stone cutting workers. The average age was $31.43 \pm 9.18$ years and the average duration of work experience as stone cutter was $12.32 \pm 6.11$. A total of $50.24 \%$ participant complaints of chronic cough, $10.29 \%$ of chest pain and $31.61 \%$ of participants reported wheezes. Data Analysis showed after 3 months of Physiotherapeutic intervention there was significant difference in FEV1 FVC and FEV1/FVC.

Conclusion: The present study shows that there was a high prevalence of pulmonary functions impairment among stone cutting worker in North Gujarat and Physiotherapy measures can be used as an adjacent to minimize this problem.
\end{abstract}

Key Words: Stone cutting workers, Pulmonary Function impairment, Pulmonary Function test, North Gujarat.

\section{INTRODUCTION}

Occupational exposure to dust is a well known phenomenon, especially in developing countries ${ }^{[1,2]}$. Although sources of air pollutants may include power plants, marble factories, cement factories, refineries and petrochemical industries, the emission of particulates is quite high from quarries ${ }^{[3]}$. Stone cutting process at construction sites convert the stone into masses and blocks (by cutting, shaping, breaking, processing, polishing, removal of sections, etc.) into desirable sizes, patterns and degrees of finishing; this is done by using manual and mechanical work tools, for the purpose of building, decorating, factories include pneumoconiosis due to exposure to mineral dust and silicosis as a result of prolonged exposure to dust containing free silica ${ }^{[4]}$.

The Stone Cutting workers are exposed to the inhalation of dust raised by the wind, surface grinding, breaking pieces of stone, and the transit of the trucks and other transportation vehicles. The dust, in the case of marble, contains quartz which can cause silicosis, depending on the amount of quartz actually present in the dust and the diameter of free silica particles ${ }^{[5]}$. 
The health impacts of working in site have been well documented by many authors ${ }^{[6,7]}$. For instance, numerous epidemiological studies have supported the association between respiratory impairment and occupational exposure to dust ${ }^{[6]}$. Also, high prevalence of silicosis has been reported among workers engaged in construction of houses in India. According to Urom et al, ${ }^{[8]}$ the major respiratory symptoms among Stone Cutting workers include non-productive cough, chest pain, and dyspnea. Considerable pulmonary function impairments have been reported in stone cutting workers by many researchers $[9,10]$.

The study by Ghotkar, et al, [11] shows the prevalence of respiratory morbidity among stone cutting workers was $32.5 \%$, based on radiological study; the severity of pulmonary function impairment was remarkably associated with increasing age, duration of exposure to dust, smoking status and presence of chronic obstructive airways disease on radiological study. It was shown that dusts generated from granite cutting contain $71 \%$ silica $[12,13]$. The occupationally related pulmonary diseases are most likely due to the deposition of dust in the lung and are influenced by the type of dusts, the period of exposure, concentration and size of the aerial dust in the breathing area ${ }^{[14]}$.

In the North Gujarat construction site workers for building house are at higher risk of occupational diseases due to the lack of awareness of safety rules and their enforcement. So, it is essential to make the workers understand the health related risks associated with stone cutting, due to lack of legislation governing the environmental performance of Stone Cutting Corporations. There is also scarcity of research and data about occupational health problems among Stone Cutting workers in North Gujarat and not a single awareness studies have been done.

Diaphragmatic breathing is one of the most widely used and studied exercises in clinical practice. It aims to improve pulmonary ventilation, mainly to the dependent zones of the lungs by promoting greater respiratory displacement of the abdominal compartment ${ }^{[15]}$

The output of this research will be an approach to improve our knowledge about occupational health in North Gujarat and will have implications for developing and implementing health and safety interventions and policies within construction site workers and for developing new guidelines for health and safety of stone cutting workers. It will also be useful for supervisor, managers, policy makers, architect, contractors and employees on greater understanding of the personal and environmental factors that influence workers health and will form a base for further research and training in the field of occupational health and safety in the future.

This work was aimed to determine the prevalence of pulmonary problems, and impairment of lung function among stone cutting workers at construction site in North Gujarat, and to identify the risk factors associated with it. The overall objective is the promotion of Occupational Health in North Gujarat through improvement of work conditions of construction site workers to prevent work related health problems.

\section{MATERIAL AND METHODOLOGY Study design:}

This is a cross-sectional study with analytical component among stone cutting workers at construction site in North Gujarat.

\section{Study setting:}

The present study was exhausted 12 construction site located in North Gujarat. These 12 construction sites constitute a non random sample of all construction sites they share the identical geographic, climatic and socioeconomic conditions and that they are using the identical instruments and machines. The construction workers are exposed to multiple risks at working places; they're exposed to physical, chemical, biological, ergonomic hazards. 


\section{Study population and study sample:}

All workers within the selected 12 working place were recruited within the study. They were 408 male workers work inside and outside at the workplace, workers have various tasks; some are directly work inside with the most cutting machine, others involved in manual stone hand polishing and pilling. Working place is mostly open from 8:30 am to 4:30 pm an six days per week.

\section{Study period:}

The study was conducted from $1^{\text {st }}$ September to $31^{\text {st }}$ December 2019. We have selected September - December months because it is a season when a maximum number of workers are usually available at working sites due to increased demand for houses and buildings for next year.

\section{Outcome measures:}

Pulmonary function tests

\section{Data collection procedure:}

All available workers were personally interviewed by using self formulated questionnaires in which we collected data about their socio demographic characteristics, full occupational history, working conditions/environment, and health related complaints.

All the workers were informed about the study and requested to sign the consent form.

Each worker was evaluated prior to instructions and after 3 months.

Medical checkup of workers were done including chest clinical examination.

The chest X-ray films were taken per standard radiographic procedures for screening.

All the participants were underwent weight and height measurements and after that pulmonary function test (spirometry) was performed. A conveyable computerized Spirometer was used. Spirometry was performed by trained researcher using a spirometer and following standard procedures [16, 17].The test procedure was explained to the worker and an instruction of the test procedure was given. The worker were allowed to sit down quietly for 10 minutes to become mentally and physically relaxed before testing. The most effective forced expiratory volume in one second (FEV 1) and compelled vital capacity (FVC) were recorded and therefore the FEV 1 /FVC ratio was calculated.

After that all the workers were taught how to perform deep breathing exercises in sitting position. Instructions were given by physiotherapists to place their hands on abdomen on rectus abdominis muscle just below anterior costal margin so they can feel the air entering in the bases of lungs and they are also instructed to keep the shoulders still, and aiming for the maximum amount movement of your ribs upwards and outwards as possible.

Along with that they are instructed to wear the facemask during stone cutting and also to quit the smoking.

Ethical Approval: The study was approved by Institutional Ethical Committee.

\section{Data management and analysis:}

Data were analyzed by using the Statistical Package for Social Science (SPSS 22). Continuous variables are expressed as mean and variance. Categorical variables are expressed as frequencies and percentage.

\section{RESULTS}

Table 1 shows demographic data and working condition of the workers. Among them $81.9 \%$ of the studied participants were older than 25 years, and $18.1 \%$ was aged 25 years and fewer. The mean age was $31.43 \pm$ 9.18 years. All participants were males, and $63.48 \%$ of them were married. Among them $63.48 \%$ participants were currently cigarette smokers. As regard chest complaints, $10.29 \%$ and $50.24 \%$ of workers reported chronic cough, pain and wheezes respectively. 
Table: 1 Description of occupational history and working condition

\begin{tabular}{|c|c|c|}
\hline Socio-demographic characteristics & Number & Percentage (\%) \\
\hline $\begin{array}{l}\text { Age group (in years) } \\
21-30 \\
31-40 \\
41-50 \\
50+ \\
\text { Age (mean } \pm \text { SD) }\end{array}$ & $\begin{array}{l}255 \\
89 \\
41 \\
23 \\
31.43 \pm 9.18 \\
\end{array}$ & $\begin{array}{l}62.5 \\
21.81 \\
10.04 \\
5.63\end{array}$ \\
\hline $\begin{array}{l}\text { Residence: } \\
\text { Urban } \\
\text { Rural }\end{array}$ & $\begin{array}{l}228 \\
180\end{array}$ & $\begin{array}{l}55.88 \\
44.11\end{array}$ \\
\hline $\begin{array}{l}\text { Marital status } \\
\text { Single } \\
\text { Married } \\
\text { Divorced }\end{array}$ & $\begin{array}{l}148 \\
259 \\
1\end{array}$ & $\begin{array}{l}36.27 \\
63.48 \\
0.25 \\
\end{array}$ \\
\hline $\begin{array}{l}\text { Education } \\
\text { Uneducated } \\
\text { School level }\end{array}$ & $\begin{array}{l}238 \\
170\end{array}$ & $\begin{array}{l}58.33 \\
41.66 \\
\end{array}$ \\
\hline $\begin{array}{l}\text { Smoking status } \\
\text { Current smoker } \\
\text { Current non smoker }\end{array}$ & $\begin{array}{l}259 \\
149\end{array}$ & $\begin{array}{l}63.48 \\
36.52\end{array}$ \\
\hline $\begin{array}{l}\text { Complaints of chronic cough } \\
\text { Yes }\end{array}$ & 205 & 50.24 \\
\hline $\begin{array}{l}\text { Complaints of chest pain } \\
\text { Yes }\end{array}$ & 42 & 10.29 \\
\hline $\begin{array}{l}\text { Complaints of wheezes } \\
\text { Yes }\end{array}$ & 129 & 31.61 \\
\hline $\begin{array}{l}\text { Lung function } \\
\text { Normal spirometry } \\
\text { Abnormal spirometry }\end{array}$ & $\begin{array}{l}49 \\
359\end{array}$ & $\begin{array}{l}12.01 \\
87.99\end{array}$ \\
\hline
\end{tabular}

Table 2 shows that the mean duration of labor experience of the studied participants were $13 \pm 9.1$ years with the work duration ranging from a minimum of 1 year to a maximum of 40 years following $(42.89 \%)$ of participants were involved in working over 8 hours daily.

Table: 2 Description of type of work and duration of work

\begin{tabular}{|l|l|l|}
\hline Type of work and working conditions & Number & Percent (\%) \\
\hline Duration of work: & & \\
<10yrs & 126 & 30.88 \\
11-20yrs & 186 & 45.58 \\
>21yrs & 96 & 23.52 \\
Duration of work in year (mean +-SD) & $12.32 \pm 6.11$ & \\
\hline Work more than 8 hours daily: & & \\
Yes & 175 & 42.89 \\
No & 233 & 57.10 \\
\hline
\end{tabular}

Table 3: Analysis of spirometry test

\begin{tabular}{|l|l|l|l|l|l|l|l|}
\hline Condition & $\mathbf{N}$ & Mean & $\begin{array}{l}\text { Std. } \\
\text { Deviation }\end{array}$ & & 95\% Confidence Interval for Mean & t & $\begin{array}{l}\text { Sig. } \\
\text { v value }\end{array}$ \\
\cline { 5 - 6 } $\begin{array}{l}\text { PFT before 3 month } \\
\text { PFT after 3 month }\end{array}$ & 408 & .50245 & .69395 & .43491 & .56999 & 14.625 & .000 \\
\hline
\end{tabular}

Table 3 Analysis of spirometry test showed highly significant difference between PFT before and after 3 month $\mathrm{p}=.000 . \mathrm{t}$ - Test is used to check the statistical significant difference for PFT before and after 3 months. This shows that as the prevalence was lower among the stone cutting workers

The difference before and after 3 months, is statistically significant with $P<$ 0.01 , so it can be clearly stated that stone dust exposure increases the risk without using personal protective measures like masks and simple dust exposure control methods as water spray. Based on the study, all the workers were suggested to use safety measures decrease the risk of pulmonary diseases Analysis of variance test showed significant difference between the spirometry reports FEV1 of $4.65 \mathrm{~L}, \mathrm{FVC}$ of $5.20 \mathrm{~L}$, and FEV1/FVC ratio of 0.89 (89, $\mathrm{p}=.000(<0.01)$. Before 3 month it was significantly higher compared to workers after counseling about safety precaution. 

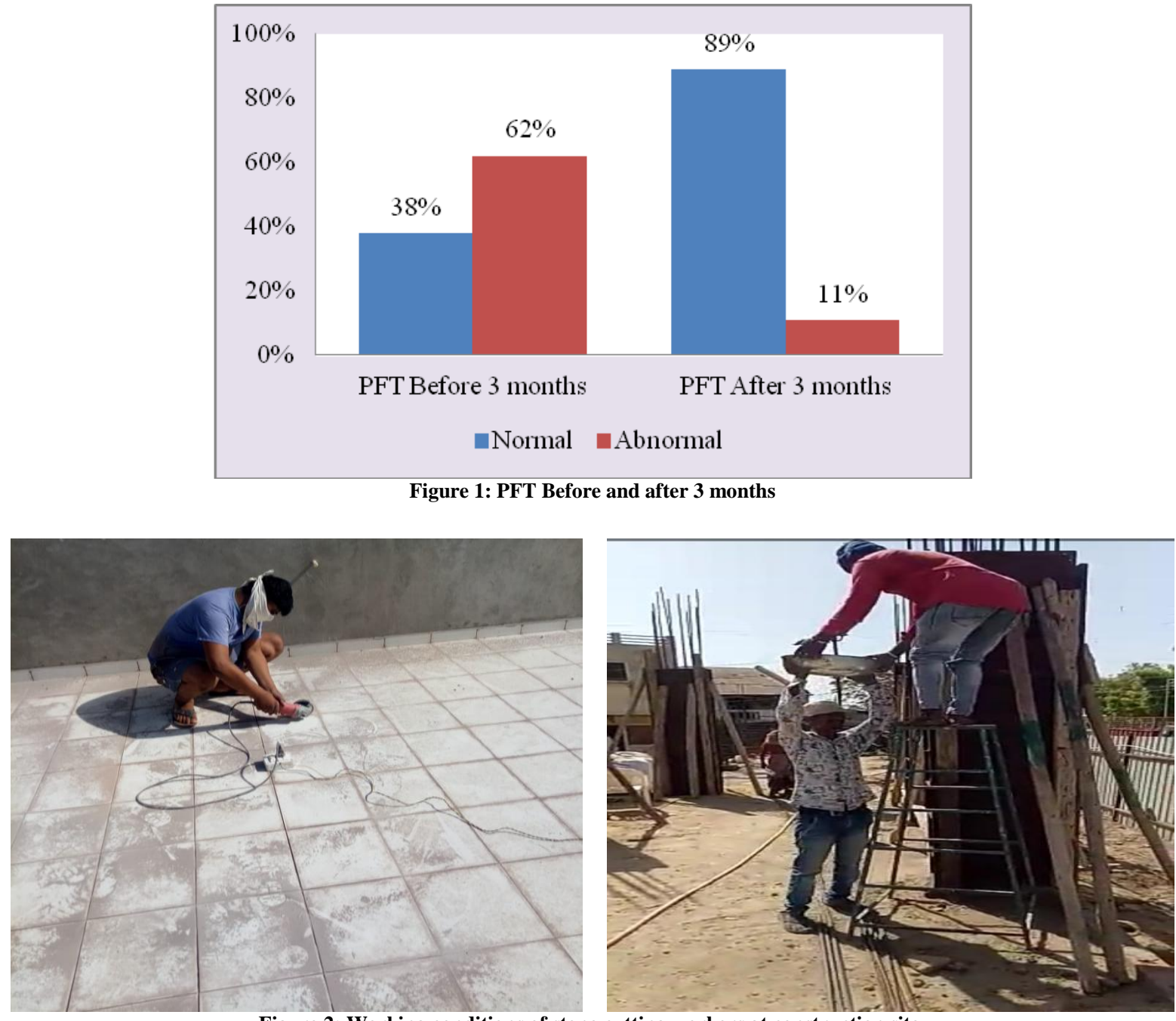

Figure 2: Working conditions of stone cutting workers at construction site.

\section{DISCUSSION}

According to the available studies and literature, the granite, marble and various other rocks and sand dust exposed sector is taken into account to be one in every of the foremost significant and most active in North Gujarat. Various procedures and operations are involved during this work including stone cutting, loading and crushing. Supported these operations, the workers are employed at different places as per the nature of work and are exposed to dust of various concentrations. The stone cutting manual workers are exposed to dust from the rocks they cut; especially during saw cutting and finishing, these dust contain silica dust ${ }^{[18]}$ which can cause pulmonary problems (silicosis). Silicosis appears after prolonged exposure to silica dust. Besides, it depends upon variety of other factors like size of the particle; concentration of silica particles in the air, duration of exposure, particle surface characteristics including the age of the particle and also the concentration of trace metals like iron. ${ }^{[19]}$

The present study was designed to judge the respiratory effects (lung function) of occupational exposure to dust in stone cutter workers.

In the current study over $57 \%$ of the participants were acting on a full time basis ( 8 hours daily), with $43 \%$ of cases working more than 8 hours each day indicating that the workers are at a high risk of exposure to the respirable stone cutting dust. Moreover, only $58.33 \%$ of the respondents had uneducated, suggesting a low level of awareness of the respondents about the health impact of the respirable stone cutting dust.

The current study showed a comparatively low prevalence of respiratory 
complains of cough (50.24), chest pain $(10.29 \%)$ and wheezes $(31.61 \%)$ compared with results of previous study conducted in Iran which reported irritating cough in $75 \%$ of the respondents ${ }^{[20]}$, also in Nigerian study among Stone Cutting workers reported high prevalence of respiratory problems; the most common problems were occasional chest pain (47.6\%), occasional cough $(40.7 \%)^{[21]}$. Our results are in accordance with a study conducted in Rio De Janeiro, Brazil ${ }^{[22]}$ which reported cough in $31.9 \%$ of workers.

The current study showed that $(12.01 \%)$ of participants had abnormal (impaired) lung function test by spirometry with the overwhelming majority of cases (11.27\%) had restrictive lung disease which mostly indicated presence of silicosis.

Among all participants workers, 266 $(65 \%)$ of the participants were working inside the site of stone cutting; more exposed to dust and $142(35 \%)$ were mostly workers outside the construction site but they are close to working area; indicating that inside workers are at a higher risk of exposure to the respirable stone cutting dust.

As per this study more number of cases with normal spirometry was found after 3 months stone cutting workers <51 years old shows that as the old age are more chances of acquiring low spirometry. On the basis of the study, all the workers were suggested to use personal protective measures like masks and simple dust exposure control methods as water spray. As simple dust exposure control measures like introduction of water spray may results in a reduction of respirable silica from stone dust and breathing exercise improve respiratory conditions. ${ }^{[17]}$

Thirdly the confounding effect of smoking and deep breathing exercises form a stage of the active cycle of breathing exercise, and tend to be carried out in a sitting position. With the effect of deep breathing exercises which allowed the air to get right to the bottom of the lungs to help mobilise secretions, by clearing secretions you significantly decrease the risk of developing a chest infection. Other benefits like Improved respiratory function (gas exchange) it increased lung volumes, improved chest expansion, Promote relaxation, Reduce reliance on oxygen therapy (if applicable), Can be carried out independently by patient with no need for supervision, Can be carried out in a number of positions, from sitting watching television, to lying in bed deep breathing beneficial in all respiratory patients, not only to mobilise secretions but to generally enhance lung function and prevent atelectasis. Respiratory conditions that are likely to benefit from thoracic expansion exercises include: Cystic Fibrosis (CF), following surgery, Pneumonia, Obstructive respiratory conditions - Chronic Obstructive Pulmonary Disease (COPD), emphysema, severe asthma, and chronic bronchitis.

\section{CONCLUSION}

The study concluded that chronic exposure to hazards from cutting, shaping, breaking, processing, polishing of stone may increase susceptibility to respiratory problems and impaired lung function. And not using personal protective measures like masks and simple dust exposure control methods as water spray increased length of service as additional predisposing risk factors. After Suggested mitigating measures include provision of safety measures (e.g., face mask), physiotherapy management in form of Deep breathing exercise, discouraging workers from smoking through public health education, frequent assessment of lung functions and redeployment of workers with severely reduced lung functions to other less hazardous occupations, and above all, provision of legislative instrument by the government making establishment of construction site workers without adequate provision of necessary safety measures a punishable offence.

\section{Acknowledgement: None}

Conflict of Interest: None 
Source of Funding: None

\section{Ethical Approval: Approved}

\section{REFERENCES}

1. Aigbedion I. Potential for rock-polishing enterprises in southwestern Nigeria. Environmental Geology. 2006; 52(4):715718.

2. Fatusi A, Erhabor G. Occupational health status of sawmills workers in Nigeria. Journal of the Royal Society of Health. 1996; 116(4):232-236.

3. Olusegun O, Adeniyi A, Adeola G. Impact of Granite Quarrying on the Health of Workers and Nearby Residents in Abeokuta Ogun State, Nigeria. Ethiopian Journal of Environmental Studies and Management. 2009; 2(1).

4. ILO, Committee on the Application of Standards - 12/6/2014 - Bangladesh Labor Standards [ILO Convention 82]. International Labor Rights Case Law. 2015; 1(1):123-132.

5. Ulm K, Gerein P, Eigenthaler J, Schmidt S, Ehnes H. Silica, silicosis and lungcancer: results from a cohort study in the stone and quarry industry. International Archives of Occupational and Environmental Health. 2004;77(5).

6. Oxman A, Muir D, Shannon H, Stock S, Hnizdo E, Lange H. Occupational Dust Exposure and Chronic Obstructive Pulmonary Disease: A Systematic Overview of the Evidence. American Review of Respiratory Disease. 1993; 148(1):38-48

7. Cotes J. Medical Research Council Questionnaire on Respiratory Symptoms (1986). The Lancet. 1987; 330(8566): 1028.

8. Urom S, Antai A, Osim E. Symptoms And Lung Function Values In Nigerian Men And Women Exposed To Dust Generated From Crushing Of Granite Rocks In Calabar, Nigeria. Nigerian Journal of Physiological Sciences. 2005;19(1)

9. Malmberg P, Hedenstrom H, Sundblad B. Changes in lung function of granite crushers exposed to moderately high silica concentrations: a 12 year follow up.
Occupational and Environmental Medicine. 1993; 50(8):726-731.

10. Ng T, Tsin T, O'Kelly F, Chan S. A Survey of the Respiratory Health of Silica-exposed Gemstone Workers in Hong Kong1,2. American Review of Respiratory Disease. 1987;135(6):12491254.

11. GhotkaR V., Maldhure B. and Zodpey S.: Involvement of lung and lung function tests in Stone Stone Cutting workers. Ind. J. Tub., 42: 155-60, 1995.

12. Deborah S.: Breathtaking: Premature Mortality due to Particulate air pollution in 239 America Cities. New York. Natural Resources Defence Council, 14-5, 1996.

13. Respiratory Health Effects from Ambient Silica Exposure: A Benchmark Dose Analysis. The Annals of Occupational Hygiene. 1997;

14. Mengesha Y, Bekele A. Relative chronic effects of different occupational dusts on respiratory indices and health of workers in three Ethiopian factories. American Journal of Industrial Medicine. 1998; 34(4):373-380.

15. Vieira D, Mendes L, Elmiro N, Velloso M, Britto R, Parreira V. Breathing exercises: influence on breathing patterns and thoracoabdominal motion in healthy subjects. Brazilian Journal of Physical Therapy. 2014;18(6):544-552.

16. Enright P, Johnson L, Connett J, Voelker H, Buist A. Spirometry in the Lung Health Study: 1. Methods and Quality Control. American Review of Respiratory Disease. 1991; 143(6): 1215-1223.

17. Gottesfeld P, Nicas M, Kephart J, Balakrishnan K, Rinehart R. Reduction of Respirable Silica Following the Introduction of Water Spray Applications in Indian Stone Crusher Mills. International Journal of Occupational and Environmental Health. 2008; 14(2):94103.

18. Castranova V, Vallyathan V, Ramsey D, McLaurin J, Pack D, Leonard S et al. Augmentation of Pulmonary Reactions to Quartz Inhalation by Trace Amounts of Iron-Containing Particles. Environmental Health Perspectives. 1997; 105:1319. 
19. Marshaallah A., MohammaD R.Z. and Ali A.F.: Prevalence of Silicosis among workers in stone-cutter and Silica Powder Production Factories. Tanaffos, 5: 31 - 6, 2006.

20. Nwibo A., Ugwuja E., Nwambeke N., et al.: Pulmonary Problems among Stone Cutting Workers of Stone Crushing Industrial Site at Umuoghara, Ebonyi State, Nigeria. The International Journal of Occupational and Environ-mental Medicine, 3: 178-85, 2012.

21. Lemele A., De araujo A.J., Lapa e S.J.R., et al.: Respiratory Symptoms and
Spirometric Tests of Stone Cutting workers in Rio de Janeiro. Rev. Assoc. Med. Bras., 40: 23-35, 1994.

22. Mathur M.L.: Silicosis among sand stone Cutting workers of a desert district Jodhpur. Ann. Nat. Acad. Med. Sci., 32: 113-8, 1996.

How to cite this article: Solanki V, Barot K, Chaudhari $\mathrm{P}$ et.al. Pulmonary function impairment among stone cutting workers in North Gujarat. Int J Health Sci Res. 2021; 11(6): 39-46. DOI: https://doi.org/10.52403/ ijhsr.20210607 